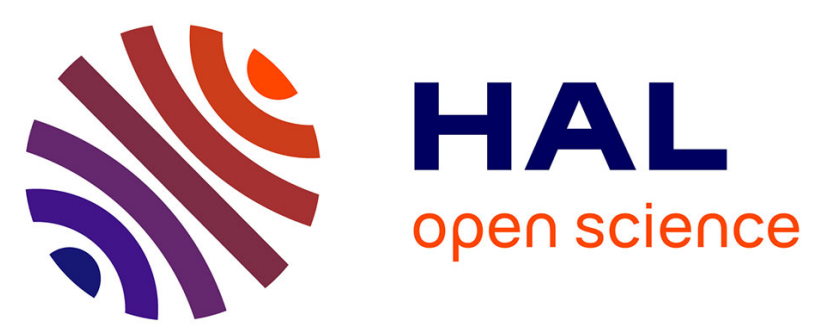

\title{
Effects of ACE inhibition on circulating endothelial progenitor cells, vascular damage, and oxidative stress in hypertensive patients
}

Francesco Cacciatore, Giuseppe Bruzzese, Dino Franco Vitale, Antonio Liguori, Filomena Nigris, Carmela Fiorito, Teresa Infante, Francesco Donatelli, Pellegrino Biagio Minucci, Louis Joseph Ignarro, et al.

\section{To cite this version:}

Francesco Cacciatore, Giuseppe Bruzzese, Dino Franco Vitale, Antonio Liguori, Filomena Nigris, et al.. Effects of ACE inhibition on circulating endothelial progenitor cells, vascular damage, and oxidative stress in hypertensive patients. European Journal of Clinical Pharmacology, 2011, 67 (9), pp.877-883. 10.1007/s00228-011-1029-0 . hal-00683510

\section{HAL Id: hal-00683510 https://hal.science/hal-00683510}

Submitted on 29 Mar 2012

HAL is a multi-disciplinary open access archive for the deposit and dissemination of scientific research documents, whether they are published or not. The documents may come from teaching and research institutions in France or abroad, or from public or private research centers.
L'archive ouverte pluridisciplinaire $\mathbf{H A L}$, est destinée au dépôt et à la diffusion de documents scientifiques de niveau recherche, publiés ou non, émanant des établissements d'enseignement et de recherche français ou étrangers, des laboratoires publics ou privés. 
Revised - Form Plane

\section{Effects of ACE inhibition on circulating endothelial progenitor cells,} vascular damage and oxidative stress in hypertensive patients\#

Francesco Cacciatore MD, PhD, MPH*a, Giuseppe Bruzzese, MD $^{\mathrm{b}}$, Dino Franco Vitale, MD ${ }^{\mathrm{a}}$, Antonio Liguori, $\mathrm{MD}^{\mathrm{b}}$, Filomena de Nigris, BiolD, $\mathrm{PhD}^{\mathrm{c}}$, Carmela Fiorito, $\mathrm{MB}^{\mathrm{c}}$, Teresa Infante, BiolD $^{\mathrm{c}, \mathrm{e}}$, Francesco Donatelli, MD ${ }^{\mathrm{d}}$, Pellegrino Biagio Minucci, BiolD ${ }^{\mathrm{c}}$, Louis Joseph Ignarro, $\mathrm{PhD}^{\mathrm{f}}$ and Claudio Napoli, MD, PhD, MBEth ${ }^{\mathrm{c}, \mathrm{e}}$

${ }^{a}$ Cardiovascular Rehabilitation, Salvatore Maugeri Foundation, IRCCS, Institute of Telese, 82037 Benevento, Italy.

${ }^{\mathrm{b}}$ Division of Cardiology-UTIC, Ospedale Pellegrini, ASL NA1, 80100 Naples, Italy.

${ }^{c}$ Department of General Pathology, Excellence Research Centre on Cardiovascular Diseases, Immunohematology and Transplantation Centre, $1^{\text {st }}$ School of Medicine, II University of Naples, 80138 Naples, Italy

${ }^{\mathrm{d}}$ Cardiosurgery Department, University of Milan, 20142 Milan, Italy.

${ }^{\mathrm{e}}$ Fondazione SDN, IRCCS, 80131 Naples, Italy

${ }^{\mathrm{f}}$ Department of Molecular and Medical Pharmacology, David Geffen School of Medicine; University of California, Los Angeles, CA 90095, USA

Corresponding Authors: * Francesco Cacciatore, MD, PhD, MPH, Cardiovascular Rehabilitation, Salvatore Maugeri Foundation, IRCCS, Institute of Telese Benevento CAP 82037, Italy.

francesco.cacciatore@fsm.it

Running Head: ACE inhibition and EPC on vascular damage in hypertension

Keywords: ACE inhibitors, EPC, vascular damage, hypertension 


\section{Conflict of Interest: NONE}

\# Presented in abstract form at the Annual Meeting of European Society of Atherosclerosis 2007, Helsinki, Finland and the Annual Congress of the European Society of Cardiology 2009, Barcelona (Spain). 


\section{Abstract}

Purpose: The pathogenic role of ACE inhibition in hypertensive patients regarding to endothelial progenitor cell (EPC) function is still poorly understood. The aim of the study was to evaluate both EPC number and function and their relationship to carotid intimal medial thickness (IMT) progression.

Methods: We studied 36 newly diagnosed mildly hypertensive patients free of cardiovascular disease and related risk factors without prior or concurrent therapy with ACE inhibitors. Patients were randomized to receive enalapril $20 \mathrm{mg} / \mathrm{die}(\mathrm{n}=18)$ or zofenopril $30 \mathrm{mg} / \mathrm{die}(\mathrm{n}=18)$. EPC number and migrating capacity, plasma nitrite/nitrate (NOx) and isoprostane concentrations were evaluated. Carotid intimal media thickness (IMT) was determined by ultrasonography at baseline and after 1 and 5 year follow-up.

Results: EPC number increased during the follow-up with no statistical differences between treatment groups. There was an inverse correlation between circulating EPCs and IMT increase over the time. Plasma nitrite/nitrate decreased during the study without evident differences between the treatment groups. Isoprostanes decreased more markedly in zofenopril treated patients. Multiple linear regression model demonstrated that the carotid IMT was significantly inversely correlated with EPC but not with migratory cells after adjustment for confounders.

Conclusions: The present study demonstrated that EPC levels increased during the follow-up in both groups of newly diagnosed hypertensive patients treated with ACE-inhibitors. These drugs prevented the progression of vascular damage with an inverse correlation between circulating EPC levels and IMT values. 


\section{Introduction}

In the last decade, there was a growing interest in the regenerative medicine afforded by the findings related to endothelial progenitor cells (EPCs) from bone marrow origin.[1,2] Thus, the pathobiology of EPC is an emerging field in the clinical setting of cardiovascular diseases. It has been hypothesized that EPC depression can be causally linked to the atherogenic process.[3] EPCs constitute a circulating pool of cells able to repair the dysfunctional endothelium whereas a reduced EPC pool may determine the inability to maintain adequate endothelial homeostasis. Moreover, the number and the functional activity of EPCs have been reported to decrease with hypertension, diabetes mellitus and the coexistence of multiple classical cardiovascular risk factors. [4-11]. Levels of EPCs are also inversely correlated to progression of coronary heart disease.[12] There are some preclinical studies suggesting that ACE inhibition may have potential effects on EPC. [13-15] Since ACE inhibitors are widely used in cardiovascular therapy, this promoted further investigation into the effects of such compounds on circulating EPC and their role in vascular healing, repair, and post natal neovascularization. ACE inhibitors may have a pivotal role in the management of atherosclerotic-related diseases independent of their vasodilating and hypotensive effects. Experimental studies show that these drugs can attenuate the development of atherosclerosis in a wide range of species, the most effective being those containing the antioxidant sulfhydryl group.[16-20]

Here, we used a previous clinical trial [21] on ACE inhibition and vascular damage to study EPC number and function and the relation to carotid intimal medial thickness (IMT) progression over the time. 


\section{Methods}

\section{Participants and measurements}

We studied 36 newly diagnosed mildly hypertensive patients; this population comes from a previously published ongoing study [21] involving 48 patients and started in 2001. Exclusion criteria included the presence of other classical risk factors for coronary heart disease (eg, diabetes/impaired glucose tolerance and hyperlipidemia); prior or concurrent therapy with ACE inhibitors, antiplatelet drugs, or anticoagulants; history of ischemic events; or refusal to grant informed consent. Patients were enrolled if they had systolic BP >160 mmHg and/or diastolic BP $>95 \mathrm{mmHg}$. Hyperlipidemia was defined as having total cholesterol >220 $\mathrm{mg} / \mathrm{dL}$, or LDL cholesterol $>140 \mathrm{mg} / \mathrm{dL}$, or triglyceride $>150 \mathrm{mg} / \mathrm{dL}$, and/or taking antihyperlipidemic medications. We used a simple randomization scheme with treatment assignment determined by computerized random number generation in a sequential manner and then provided to the clinical investigators in sealed envelopes. Follow-up measurements were scheduled at 1 and 5 years. The trial protocol followed the principles outlined in the Declaration of Helsinki and approved by the Local Ethical Committee.

\section{Carotid ultrasonography measurements}

All carotid ultrasonography measurements were made by 2 investigators (G.B. and A.L.) to eliminate interobserver variability, blinded to treatment randomization, as previously described. [21] Carotid artery IMT was measured by high-resolution B-mode ultrasonography, with a 7.5-MHz high-resolution transducer (Sonos-5500 system; Philips Medical Systems, Andover, MA) as described previously. [22,23] The carotid arteries were carefully examined for wall changes in the longitudinal and transverse views. The common carotid artery, carotid bulb, and internal and external arteries were examined. Presence of carotid atherosclerotic lesions (plaques or shadowing) was determined from scans of all right and left carotid artery segments (common carotid artery, bifurcation, and internal carotid artery). The presence of plaques was defined during ultrasound 
reading based on wall thickness and arterial wall roughness, loss of alignment, or protrusion into the lumen. Calcification or mineralization, another indicator of atherosclerosis, was based on acoustic shadowing. Right and left common carotid artery wall areas were calculated as the total artery area minus the lumen area assuming a circular lumen and an outer artery structure that was either circular or elliptical. The IMT of the far wall was defined as the distance from the lumen-intima interface (leading edge of the first echogenic line) to the media-adventitia interface (leading edge of the second echogenic line). We measured the IMT of the common carotid arteries bilaterally at 3 points (at 1,2, and $3 \mathrm{~cm}$ proximal to the carotid bifurcation); the averaged value was taken as the carotid IMT. IMT values for the 3 different projections were averaged to obtain the mean maximum IMT (MM-IMT).

Lesions of apparent plaque appearing either as faint gray echoes (soft plaques) or bright white echoes (calcified plaque) protruding into the lumen, were always excluded from the IMT measurement.[24]

\section{Blood pressure measurements}

Blood pressure (BP) was measured at baseline and during the 2 subsequent examinations with a mercury sphygmomanometer in a standardized fashion, after 10 minutes of rest with the subject in the supine position.[25] Systolic and diastolic BPs (mmHg) were defined according to Korotkoff sounds I and V. All BP measurements were done just before carotid ultrasound measurements and were performed after drug administration by a physician who was blinded as to the patients' profiles and treatment assignments.

\section{Evaluation of plasma nitrite/nitrate and isoprostane concentrations}

Plasma nitrite/nitrate (NOx) levels were measured with the classical Griess method, as previously described.[25] Amounts of plasma nitrite were estimated by a standard curve obtained from enzymatic conversion of $\mathrm{NaNO} 3$ to nitrite. Isoprostanes (8-iso-PGF2 $\alpha$ ) were measured from 
plasma samples by using a commercially available immunoassay (Cayman Chemical, Ann Arbor, MI) according to the manufacturer's instructions.[25]

Measurement of EPC number (culture assay)

Mononuclear cells were isolated by density gradient centrifugation with Biocoll (Biochrom, Berlin, Germany) from $20 \mathrm{~mL}$ peripheral blood, as previously described.[26] After isolation, $4 \times 10^{6}$ mononuclear cells were plated on 24-well culture dishes coated with human ibronectin (SigmaAldrich, Munich, Germany) and maintained in endothelial basal medium (Cambrex, Walkerville, MD, USA) supplemented with endothelial growth medium and $20 \%$ fetal calf serum. After $4 \mathrm{~d}$ in culture, non-adherent cells were removed by thorough washing with phosphate-buffered saline (PBS).

\section{Measurement of functional capacity of EPCs (migrating capacity)}

Isolated EPCs were detached using $1 \mathrm{mmol} / \mathrm{L}$ ethylenediaminetetraacetic acid in PBS (pH 7.4), harvested by centrifugation, resuspended in $500 \mu \mathrm{L}$ endothelial basal medium, counted, and placed in the upper chamber of a modified Boyden chamber $(2 \times 104$ cells; BD Bioscience, Milan, Italy). The chamber was placed in a 24 -well culture dish containing endothelial basal medium, $20 \%$ fetal calf serum, and human recombinant vascular endothelial growth factor (VEGF) $(50 \mathrm{ng} / \mathrm{mL}$; R\&D Systems, Minneapolis, MN, USA). After $24 \mathrm{~h}$ incubation at $37^{\circ} \mathrm{C}$, the lower side of the filter was washed with PBS and fixed with 2\% paraformaldehyde. For quantification, cell nuclei were stained with 4',6'-diamidino-2-phenylindole. Cells migrating into the lower chamber were counted manually in several random microscopic fields. [26] Measurements were blinded to treatment randomization 


\section{Statistical analysis}

Data are presented as mean $\pm \mathrm{SD}$. ANOVA for repeated measure was used to test the effect of treatment (enalapril vs zofenopril) over the time (Baseline, 1 year and five years) on systolic and diastolic BP, IMT, EPCs, Migratory cells, NOx and PGE $_{2 a l p h a}$ in the table are reported statistical significance for the treatment effect, time effect and interaction between treatment and time. In order to assess the association between IMT versus EPC and/or Migratory cells controlling for confounder effect of treatment, time and other variables, we used linear regression analysis with robust variance estimation clustering for each patients in order to compensate for the correlation between the repeated measures.[27] A p value $<0.05$ was considered as statistically significant. Analysis was performed using STATA 10 software. 


\section{Results}

The mean age of the patients was $41.6 \pm 2.6$ (range 36-46). No significant difference in age, gender, family history of an ischemic event ( $\mathrm{CHD}$, peripheral arterial disease, or stroke), history of smoking, sedentary lifestyle, or medication used (calcium antagonist; 2 in enalapril and 2 in zofenopril group) were present at baseline between the 2 groups [21]. Moreover, no differences were present for others risk factors such as total cholesterol, triglycerides, high-density lipoprotein cholesterol, or LDL-cholesterol. [21] No patients had diabetes or were in treatment with statin or aspirin. The compliance to pharmacological treatment was good without withdrawn during the follow-up.

EPCs increased during the follow-up with no statistical differences between treatment groups.

(Table 1 and Figure 1). Migrating capacity of EPCs did not change during the study and no differences were evident between the treatment groups. (Table 1 and Figure 1). Plasma nitrite/nitrate (NOx) decreased significantly during the study while no differences were evident between the treatment groups. (Table 1 and Figure 1). Isoprostanes (8-iso-PGF2 $\alpha$ ) decreased significantly during the study more markedly in zofenopril treated patients. (Table 1 and Figure 1). Intimal media thickness increased during the follow-up and this effect was more evident in the group of patients treated with enalapril even if this difference did not reach statistical significance when compared to zofenopril treated group. A statistically significant interaction between treatments and time suggesting a time related effect of pharmacological treatment in reducing IMT progression. (Table 1 and Figure 1). As expected, a significant reduction of systolic and diastolic blood pressure during the study was obtained with no statistical differences between treatment groups also considering the effect of interaction between treatment and time. (Table 1 and Figure 1).

In order to assess the correlation between IMT and EPCs and migratory cells, adjusted for all other covariates, we built a multiple linear regression model with IMT as independent variable and EPC and migratory cells as effect modifiers and all the remaining variables listed in the table as 
confounder. The multiple linear regression model showed that the IMT was significantly inversely correlated with EPC but not with migratory cells after adjustment for confounders. (Table 2 and

\section{Figure 2)}

\section{Discussion}

The major findings of our study are: 1) an EPC increase during the follow-up in both groups of patients treated with enalapril and zofenopril, 2) an inverse correlation between circulating EPCs and IMT increase over the time, 3) a plasma nitrite/nitrate decrease without evident differences between the treatment groups and 4) a isoprostanes decrease more evidently in zofenopril treated patients.

Migrating capacity of EPCs did not change during the study and no differences were evident between the treatment groups. Multivariate analysis demonstrated that vascular damage was significantly inversely correlated with EPCs levels but not with migrating capacity after adjustment for confounders.

A previous cross-sectional study, demonstrated an association of EPC migration, age and mean arterial blood pressure on carotid intimal thickning, they also found an inverse correlation with EPC number $(\mathrm{r}=-0.349)$ but with no statistical significance $(\mathrm{p}=0.063)$ demonstrating an age related decrease in EPC function and a possible effect on vascular remodelling.[28]

Another study [29] demonstrated that a significantly higher carotid mean maximum intima-media thickness, prevalence of carotid plaque and a lower number of circulating CD $34^{+} / \mathrm{KDR}^{+} \mathrm{EPCs}$ was found in stroke patients, compared with controls. In stroke patients, circulating $\mathrm{CD}^{+} 4^{+} / \mathrm{KDR}^{+} \mathrm{EPCs}$ count correlated negatively with carotid IMT, and was an independent risk factor for increased carotid IMT $>1 \mathrm{~mm}$ and the presence of carotid plaque.

Another very recent study [30] established that telmisartan shows a more potent anti-inflammatory effects than the ACE inhibitor ramipril and the two drugs did not show a differential effects on EPCs. 
Since the expression of ACE may regulate primitive hemangioblasts derived from human stem cells, [14] the renin-angiotensin-aldosterone axis can be therefore exploited to direct the EPC fate during vascular regeneration. This issue may constitute an important clinical implication of ACE therapy on vascular damage occurring in hypertensive patients.

ACE inhibitors may have a pivotal role in the management of atherosclerotic-related diseases independent of their vasodilating and hypotensive effects. Experimental studies showed that these drugs can attenuate the development of atherosclerosis in a wide range of species, the most effective being those containing the antioxidant sulfhydryl group. [16-20] Different ACE inhibitors have quite different chemical functional groups, and these structural variations may account for different in vivo and in vitro effects. The ACE inhibitor captopril has a sulfhydryl group to coordinate the zinc ion of the active site, enalaprilat has a carboxylate group, and zofenopril has 2 sulfhydryl groups. [31-32] Sulfhydryl ACE inhibition stimulates the NO activity and decreases oxidative stress in human endothelial cells [33] and in patients with essential hypertension.[21] Zofenopril increases NO production in endothelium, decreases atherosclerotic development, and reduces reactive oxygen species, [34-37] as well as susceptibility to oxidation of plasma lowdensity lipoproteins (LDL) and formation of oxidation-specific epitopes in the arterial wall and atherogenesis in apolipoprotein E knockout mice. [35] The meaning of NOx levels would be qualitatively rather than quantitatively. However, repeated assays in same subjects have high sensitivity. In the present study, as expected, the untreated state of hypertension was associated to increased levels of NOx, after both treatments, NOx level decreased indicating that a normalization of blood pressure was associated to restoring effects of the NO pathway.

Circulating EPCs could play an important role in accelerating endothelialization at areas of vascular damage, and EPC function would be a viable strategy for assessing reparative ability. Consistently, some studies established that EPCs are affected both in number and function by several cardiovascular risk factors as well as various cardiovascular disorders, such as hypertension, hypercholesterolemia, and coronary heart disease [38]. 
Our study had some limitations. First, we used plasma storage collected from another clinical trial. [21] Another study limitation would be the limited power of the study due to a small group of patients.

In conclusion, our study demonstrated that EPC levels increased during the treatment in both groups of patients treated with ACE-inhibitors indicating that these drugs prevent vascular damage in newly hypertensive treated patients not only reducing blood pressure but also acting on circulating EPCs.

Author Contributions Dr. Cacciatore, Dr. Vitale and Prof. Napoli played a major role in the writing of the manuscript. Dr. Cacciatore and Dr. Vitale were also responsible for statistical analysis. Dr. Liguori, and Dr. Bruzzese had the overall responsibility for all in-hospital activities, in particular coordination of the clinical team, permissions to access medical records, obtaining informed consent, and clinical protocols. Dr. de Nigris, Dr. Fiorito, Dr. Infante, and Dr. Minucci provided execution and interpretation of clinical laboratory measurements. Prof. Napoli and Prof. Ignarro were involved in the first serie of studies addressing the vascular effects of ACE inhibitors thus providing the rationale and aim of the present study. However, a strong support on the detailed design of the study and its follow-up was done by Prof. Donatelli, Dr. Liguori and Dr. Cacciatore. None of the Authors have conflict of interest in the connection of this study.

Acknowledgments. This work was supported in part by grants from the Progetto di Rilevante Interesse Nazionale Ministero Italiano Università e Ricerca 2006 [Code 0622153_002 "Meccanismi fisiopatologici di danno vascolare/trombotico ed angiogenesi” (to C.N.), Ricerca Finalizzata del Ministero della Salute 2007 (to F.C.) and the Fondation Jerome Lejeune, France (to C.N.). 


\section{References}

1. Napoli C, Balestrieri A, Ignarro LJ (2007). Therapeutic approaches in vascular repair induced by adult bone marrow cells and circulating progenitor endothelial cells. Curr Pharm Des.13:3245-3251.

2. Napoli C, Cacciatore F (2009). Novel pathogenic insights in the primary prevention of cardiovascular disease. Prog Cardiovasc Dis.51:503-523.

3. Fadini GP, Coracina A, Baesso I, et al. (2006). Peripheral blood CD $34^{+} \mathrm{KDR}^{+}$endothelial progenitor cells are determinants of subclinical atherosclerosis in a middle-aged general population . Stroke. 37:2277-2282

4. Heitzer T, Schlinzig T, Krohn K, Meinertz T, Munzel T. (2001). Endothelial dysfunction, oxidative stress, and risk of cardiovascular events in patients with coronary artery disease. Circulation 104:2673-2678.

5. Vasa M, Fichtlscherer S, Aicher A, et al (2001). Number and migratory activity of circulating endothelial progenitor cells inversely correlate with risk factors for coronary artery disease. Circ Res.89:E1-7.

6. Liguori A, Fiorito C, Balestrieri ML, et al. (2008). Functional impairment of hematopoietic progenitor cells in patients with coronary heart disease. Eur J Haematol.80:258-264.

7. Kinnaird T, Stabile E, Zbinden S, Burnett MS, Epstein SE. (2008). Cardiovascular risk factors impair native collateral development and may impair efficacy of therapeutic interventions. Cardiovascular Research 78:257-264.

8. Spinetti G, Kraenkel N, Emanueli C, Madeddu P. (2008). Diabetes and vessel wall remodelling: from mechanistic insights to regenerative therapies. Cardiovascular Research 78:265-273.

9. Feihl F, Liaudet L, Levy BI, Waeber B. (2008) Hypertension and microvascular remodelling. Cardiovascular Research 78:274-285.

10. Lijnen HR. (2008). Angiogenesis and obesity. Cardiovascular Research 78: 286-293. 
11. Balestrieri ML, Rienzo M, Felice F, et al. (2008). High glucose downregulates endothelial progenitor cell number via SIRT1. Biochimica et biophysica acta 1784:936-994

12. Briguori C, Testa U, Riccioni R, et al. (2010) Correlations between progression of coronary artery disease and circulating endothelial progenitor cells. FASEB J. 24:1981-1988

13. You D, Cochain C, Loinard C, et al. (2008). Combination of the Angiotensin-Converting Enzyme inhibitor Perindropil and diuretic indapamide activate postnatal vasculogenesis in spontaneously hypertensive rats. J Pharmacol Experimental Ther 325:766-773.

14. Zambidis ET, Park TS, Yu W, et al. (2008) Expression of angiotensine-converting enzyme (CD 143) identifies and regulate primitive hemangioblasts derived from human pluripotent stem cells. Blood 112:3601-3614.

15. Muller P, Kazalov A, Jagoda P, Semenov A, Bohm M, Laufs U. (2009). ACE inhibition promotes upregulation of endothelial progenitor cells and neoangiogenesis in cardiac pressure overload. Cardiovasc Res 83:106-114.

16. Napoli C, Cicala C, D'Armiento FP, et al.. (1999). Beneficial effects of ACE-inhibition with zofenopril on plaque formation and low-density lipoprotein oxidation in Watanabe heritable hyperlipidemic rabbits. Gen Pharmacol 33:467-477.

17. Chobanian AV, Haudenschild CC, Nickerson C, Drago R. (1990) Antiatherogenic effect of captopril in the Watanabe heritable hyperlipidemic rabbit. Hypertension15:327-331.

18. Hayek T, Attias J, Smith J, Breslow JL, Keidar S. (1998) Antiatherosclerotic and antioxidative effects of captopril in apolipoprotein E-deficient mice. J Cardiovasc Pharmacol $31: 540-544$.

19. Sun YP, Zhu BQ, Browne AE, et al. (2001) Comparative effects of ACE inhibitors and an angiotensin receptor blocker on atherosclerosis and vascular function. J Cardiovasc Pharmacol Ther 6:175-181. 
20. Candido R, Jandeleit-Dahm KA, Cao Z, et al. (2002) Prevention of accelerated atherosclerosis by angiotensin-converting enzyme inhibition in diabetic apolipoprotein Edeficient mice. Circulation 106:246-253.

21. Napoli C, Bruzzese G, Ignarro LJ, et al. (2008) Long-term treatment with sulfhydryl angiotensin-converting enzyme inhibition reduces carotid intima-media thickening and improbe the nitric oxide/oxidative stress pathways in newly diagnosed patients with mild to moderate primary hypertension. Am Heart J 156:1154-1162.

22. Napoli C, Lerman LO, de Nigris F, Gossl M, Balestrieri ML, Lerman A. (2006) Rethinking primary prevention of atherosclerosis-related diseases. Circulation 114:2517-2527.

23. Napoli C, Liguori A, Sorice P, et al. (1996) Relations between vasoactive hormones and diastolic function in hypertensive uraemic patients. J Intern Med. 240:389-394.

24. Persson J, Stavenow L, Wikstrand J, Israelsson B, Formgren J, Berglund G. (1992) Noninvasive quantification of atherosclerotic lesions. Reproducibility of ultrasonographic measurement of arterial wall thickness and plaque size. Arterioscler Thromb 12:261-266.

25. Napoli C, Sica V, de Nigris F, et al. (2004) Sulfhydryl angiotensin-converting enzyme inhibition induces sustained reduction of systemic oxidative stress and improves the nitric oxide pathway in patients with essential hypertension. Am Heart J. 148:e5- e13.

26. Casamassimi A, Balestrieri ML, Fiorito C, et al. (2007) Comparison between total endothelial progenitor cell isolation versus enriched Cd133+ culture. J Biochem.141:503-11.

27.Williams, R. L. (2000) A note on robust variance estimation for cluster-correlated data. Biometrics 56:645-646.

28. Keymel S, Kalka C, Rassaf T, Yeghiazarians Y, Kelm M, Heiss C. (2008) Impaired endothelial progenitor cell function predicts age-dependent carotid intimal thickening. Basic Res Cardiol. 103:582-6. 
29. Lau KK, Chan YH, Yiu KH, et al. (2007) Burden of carotid atherosclerosis in patients with stroke: relationships with circulating endothelial progenitor cells and hypertension. Journal of Human Hypertension 21:445-451.

30. Porto I, Di Vito L, De Maria GL, et al. (2009) Comparison of the effects of ramipril versus telmisartan on high-sensitivity C-reactive protein and endothelial progenitor cells after acute coronary syndrome. Am J Cardiol 103:1500-1505.

31. Kowala MC, Grove RI, Aberg G. (1994) Inhibitors of angiotensin converting enzyme decrease early atherosclerosis in hyperlipidemic hamsters. Fosinopril reduces plasma cholesterol and captopril inhibits macrophage-foam cell accumulation independently of blood pressure and plasma lipids. Atherosclerosis 108:61-72.

32. Unger T. (2002) The role of the renin-angiotensin system in the development of cardiovascular disease. Am J Cardiol 89:3A-10A.

33. Jacoby DS, Rader DJ. (2003) Renin-angiotensin system and atherothrombotic disease: from genes to treatment. Arch Intern Med 163:1155-64.

34. Scribner AW, Loscalzo J, Napoli C. (2003) The effect of angiotensin converting enzyme inhibition on endothelial function and oxidant stress. Eur J Pharmacol 482:95-9.

35. de Nigris F, D'Armiento FP, Somma P, et al. (2001) Chronic treatment with sulfhydryl angiotensin-converting enzyme inhibitors reduce susceptibility of plasma LDL to in vitro oxidation, formation of oxidation-specific epitopes in the arterial wall, and atherogenesis in apolipoprotein E knockout mice. Int J Cardiol 81:107-115.

36. Evangelista S, Manzini S. (2005) Antioxidant and cardioprotective properties of the sulphydryl angiotensin-converting enzyme inhibitor zofenopril. J Int Med Res 33:42-54.

37. Cominacini L, Pasini A, Garbin U, et al. (2002) Zofenopril inhibits the expression of adhesion molecules on endothelial cells by reducing reactive oxygen species. Am J Hypertens 15:891-895. 
38. António N, Fernandes R, Rodriguez-Losada N, et al. (2010) Stimulation of endothelial progenitor cells: a new putative effect of several cardiovascular drugs. Eur $\mathrm{J}$ Clin Pharmacol.66:219-230.

\section{LEGEND TO FIGURES}

Figure 1. Modifications during the study of parameters in enalapril-treated patients (circle \& continuous line) and zofenopril-treated patients (square \& dashed line). Data presented are mean \pm SD. Enalapril-treated patients $(\mathrm{N}=18)$ and Zofenopril-treated patients $(\mathrm{N}=18)$

Figure 2: Multivariate regression analysis evaluating the independent effect of EPC number on carotid IMT progression. 

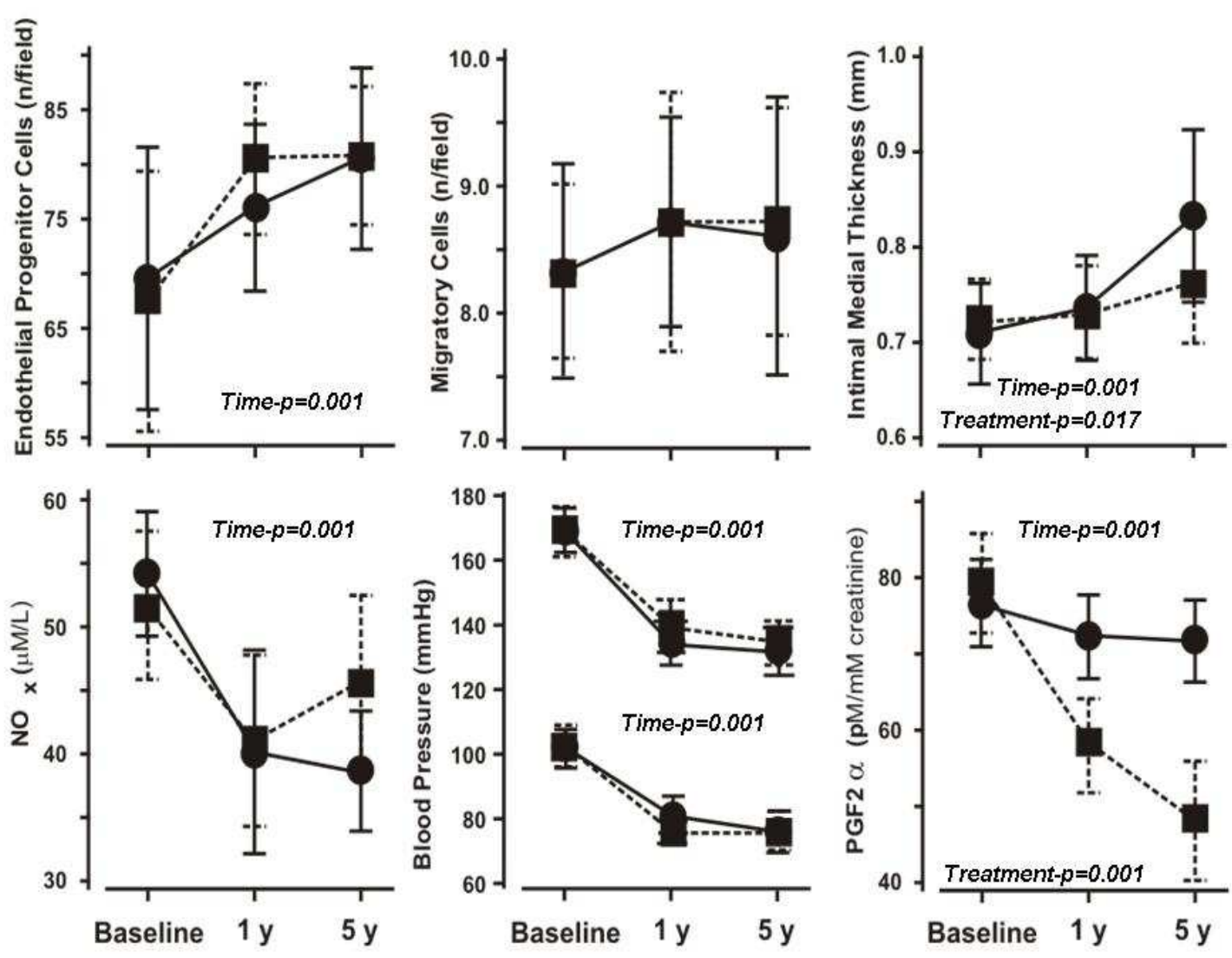


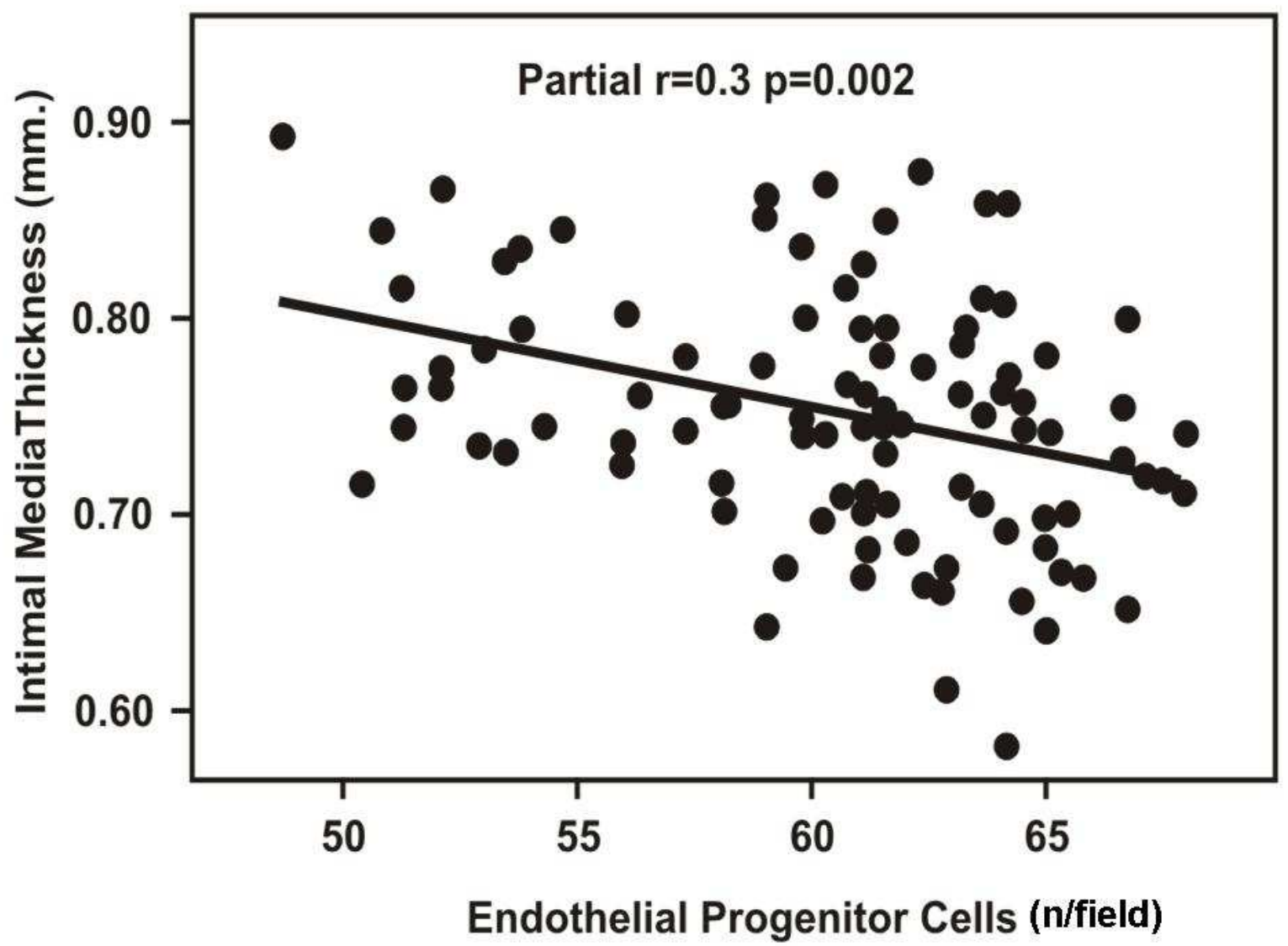


Table 1: Repeated Measure of Analysis of Variance in Enalapril (18-patients) and Zofenopril (18 patients) groups during the study.

\begin{tabular}{|c|c|c|c|c|c|c|}
\hline Variable & Baseline & 1 year & 5 year & Treatment & Time & $\begin{array}{c}\text { Interaction } \\
\text { Treatment*time }\end{array}$ \\
\hline SBP - Enalapril & $169.1 \pm 7.0$ & $134.3 \pm 6.7$ & $131.8 \pm 7.4$ & \multirow{2}{*}{$\mathrm{P}=0.092$} & \multirow{2}{*}{$\mathrm{P}=0.001$} & \multirow{2}{*}{$\mathrm{P}=0.245$} \\
\hline SBP - Zofenopril & $168.6 \pm 7.9$ & $139.6 \pm 8.3$ & $134.5 \pm 6.8$ & & & \\
\hline DBP- Enalapril & $101.9 \pm 5.8$ & $81.3 \pm 5.6$ & $75.9 \pm 6.6$ & \multirow{2}{*}{$\mathrm{P}=0.199$} & \multirow{2}{*}{$\mathrm{P}=0.001$} & \multirow{2}{*}{$\mathrm{P}=0.050$} \\
\hline DBP - Zofenopril & $102.6 \pm 8.3$ & $76.0 \pm 3.5$ & $76.2 \pm 6.1$ & & & \\
\hline IMT - Enalapril & $0.71 \pm 0.05$ & $0.74 \pm 0.05$ & $0.83 \pm 0.09$ & \multirow{2}{*}{$\mathrm{P}=0.074$} & \multirow{2}{*}{$\mathrm{P}=0.001$} & \multirow{2}{*}{$\mathrm{P}=0.017$} \\
\hline IMT - Zofenopril & $0.72 \pm 0.04$ & $0.73 \pm 0.05$ & $0.76 \pm 0.07$ & & & \\
\hline EPC- Enalapril & $69.6 \pm 12.0$ & $76.1 \pm 7.6$ & $80.6 \pm 8.4$ & \multirow{2}{*}{$\mathrm{P}=0.573$} & \multirow{2}{*}{$\mathrm{P}=0.001$} & \multirow{2}{*}{$\mathrm{P}=0.341$} \\
\hline EPC- Zofenopril & $67.5 \pm 11.9$ & $80.7 \pm 7.0$ & $80.9 \pm 7.3$ & & & \\
\hline Migr - Enalapril & $8.3 \pm 0.9$ & $8.7 \pm 0.8$ & $8.6 \pm 1.1$ & \multirow{2}{*}{$\mathrm{P}=0.819$} & \multirow{2}{*}{$\mathrm{P}=0.169$} & \multirow{2}{*}{$\mathrm{P}=0.959$} \\
\hline Migr- Zofenopril & $8.3 \pm 0.7$ & $8.7 \pm 1.0$ & $8.7 \pm 0.9$ & & & \\
\hline NO- Enalapril & $54.1 \pm 4.9$ & $40.1 \pm 8.0$ & $38.6 \pm 4.7$ & \multirow{2}{*}{$\mathrm{P}=0.122$} & \multirow{2}{*}{$\mathrm{P}=0.001$} & \multirow{2}{*}{$\mathrm{P}=0.009$} \\
\hline NO - Zofenopril & $51.6 \pm 5.8$ & $41.1 \pm 6.8$ & $45.6 \pm 6.9$ & & & \\
\hline 8-iso-PGF2 $\alpha$ Enalapril & $76.4 \pm 5.6$ & $72.4 \pm 5.4$ & $71.6 \pm 5.4$ & \multirow[b]{2}{*}{$\mathrm{P}=0.001$} & \multirow[b]{2}{*}{$\mathrm{P}=0.001$} & \multirow[b]{2}{*}{$\mathrm{P}=0.001$} \\
\hline $\begin{array}{l}\text { 8-iso-PGF2 } \alpha \\
\text { Zofenopril }\end{array}$ & $79.1 \pm 6.6$ & $57.8 \pm 6.1$ & $48.1 \pm 7.8$ & & & \\
\hline
\end{tabular}

Legend: SBP = Systolic Blood Pressure; DBP=Diastolic Blood Pressure; IMT= Intimal Media Thickness; EPC=Endothelial Progenitor Cells; Migr = Migratory Cells; NO = Plasma nitrite/nitrate; 8-iso-PGF2 $\alpha=$ Isoprostane. 
Table 2: Multivariate linear regression analysis with robust variance estimation clustering for each patient in order to compensate for the correlation between repeated measures and IMT as dependent variable.

\begin{tabular}{|l|c|c|c|}
\hline Variable & B coefficient & Robust SE & P \\
\hline EPC \# & -0.0018 & 0.0005 & 0.001 \\
\hline Treatment \# & 0.0198 & 0.0152 & 0.203 \\
\hline Time \# & 0.0861 & 0.0181 & 0.001 \\
\hline Treatment * Time \# & -0.0699 & 0.02 & 0.001 \\
\hline EPC Migration & 0.0054 & 0.0065 & 0.41 \\
\hline NOx & -0.0005 & 0.0012 & 0.678 \\
\hline 8-iso-PGF2 $\alpha$ & -0.0024 & 0.0011 & 0.04 \\
\hline Systolic BP & 0.0013 & 0.0008 & 0.1 \\
\hline Diastolic BP & 0.00005 & 0.0008 & 0.95 \\
\hline Age & 0.0013 & 0.0018 & 0.46 \\
\hline Gender & 0.0019 & 0.012 & 0.87 \\
\hline
\end{tabular}

\# Variable retained after backward hierarchical model. 